\title{
Pelatihan Metode Pembelajaran Contextual Teaching Learning untuk Meningkatkan Motivasi Belajar Siswa
}

\author{
I Made Sonny Gunawan*, Sarilah, I Made Gunawan, Kholisussa'di \\ FIPP Universitas Pendidikan Mandalika \\ *Corresponding Author: imadesonnygunawan@ikipmataram.ac.id
}

\begin{abstract}
The purpose of carrying out this community service activity is to increase the knowledge and understanding of kindergarten teachers about the application of Contextual Teaching Learning learning methods in increasing student learning motivation. The method used in this service is to provide counseling in the form of training for kindergarten teachers and provide assistance for six months. The participants in this community service activity were 6 teachers at Darul Muhsinin Kindergarten, Enjak Hamlet, Labulia Village, West Lombok Regency. The results of this community service indicate an increase in the skills of kindergarten teachers in designing and implementing effective learning methods for students that can increase student learning motivation.
\end{abstract}

\begin{abstract}
Abstrak: Tujuan dilakukannya kegiatan pengabdian masyarakat ini adalah untuk meningkatkan pengetahuan dan pemhaman guru TK tentang penerapan metode pembelajaran Contextual Teaching Learning di dalam meningkatkan motivasi belajar siswa. Metode yang digunakan dalam pengabdian ini adalah dengan memberikan penyuluhan dalam bentuk pelatihan bagi guru TK dan melakukan pendampingan selama enam bulan. Adapun peserta di dalam kegiatan pengabdian masyarakat ini adalah guru-guru di TK Darul Muhsinin, Dusun Enjak, Desa Labulia, Kabupaten Lombok Barat yang berjumlah 6 orang. Hasil dari pengabdian masyarakat ini menunjukkan adanya peningkatan keterampilan guru TK dalam mendesain dan menerapkan metode belajar efektif bagi siswa yang dapat meningkatkan motivasi belajar siswa.
\end{abstract}

\section{Article History:}

Received: 25-11-2020

Reviewed: 23-12-2020

Accepted: 03-04-2021

Published: 05-05-2021

\section{Key Words:}

Training, Contextual

Teaching Learning,

Motivation.

\section{Sejarah Artikel:}

Diterima: 25-11-2020

Direview: 23-12-2020

Disetujui: 03-04-2021

Diterbitkan: 05-05-2021

\section{Kata Kunci:}

Pelatihan, Contextual

Teaching Learning,

Motivasi.

How to Cite: Gunawan, I., Sarilah, S., Gunawan, I., \& Kholisussadi, K. (2021). Pelatihan Metode Pembelajaran Contextual Teaching Learning untuk Meningkatkan Motivasi Belajar Siswa. Jurnal Pengabdian UNDIKMA, 2(1), 59-63. doi:https://doi.org/10.33394/jpu.v2i1.3176

doi:https://doi.org/10.33394/jpu.v2i1.3176

This is an open-access article under the CC-BY-SA License.

\section{Pendahuluan}

Pendidikan berfungsi untuk mengembangkan kemampuan dan membentuk watak serta peradaban bangsa yang bermartabat dalam rangka mencerdaskan kehidupan bangsa, bertujuan untuk berkembangnya potensi peserta didik agar menjadi manusia yang beriman dan bertakwa kepada Tuhan Yang Maha Esa, berakhlak mulia, sehat, berilmu, cakap, kreatif, mandiri, dan menjadi warga negara yang demokratis serta bertanggung jawab (Hamalik, 2010). Adapun untuk mewujudkan tujuan dari pendidikan tersebut maka dibutuhkan pendekatan, metode, dan teknik pembelajaran yang tepat sasaran sesuai kebutuhan dilapangan. Terkait dengan hal tersebut maka maka sangatlah urgen pembelajaran Contextual Teaching and Learning untuk membantu guru dalam meningkatkan kemampuan siswa dikelas dengan memberikan pelatiahan tentang bagaimana menerapkan model pembelajaran Contextual Teaching and Learning. Alasan menggunakan pembelajaran Contextual Teaching and Learning karena konsep pembelajarannya menekankan pada keterkaitan antara materi pembelajaran dengan kehidupan peserta didik secara nyata, sehingga para peserta didik 
mampu menghubungkan dan menerapkan kompetensi hasil belajar dalam kehidupan sehariharinya (Mulyasa, 2006).

Disamping itu, penerapan pembelajaran kontekstual akan sangat membantu guru untuk menghubungkan materi pelajaran dengan situasi dunia nyata dan memotivasi siswa untuk membentuk hubungan antara pengetahuan dan aplikasinya dengan kehidupan mereka sebagai masyarakat. Berdasarkan pemahaman tersebut, teori pembelajaran kontekstual berfokus pada multi aspek lingkungan belajar diantaranya ruang kelas, laboratorium, tempat bekerja maupun tempat-tempat lainnya. Pendekatan Contextual Teaching and Learning akan mendorong para guru untuk memilih dan mendesain lingkungan belajar yang dimungkinkan untuk mengaitkan berbagai bentuk pengalaman sosial, budaya, fisik, dan psikologi dalam mencapai hasil belajar. Adapun di dalam suatu lingkungan yang demikian, siswa akan menemui hubungan yang sangat bermakna antara ide-ide abstrak dan penerapan praktis didalam konteks dunia nyata, konsep dipahami melalui proses penemuan, pemberdayaan, dan hubungan.

Mengingat pembelajaran Contextual Teaching Learning merupakan salah satu pembelajaran yang memberikan makna seutuhnya sehingga akan memiliki dampak yang positif pada siswa terkait dengan hal tersebut maka pembelajaran tersebut akan dapat menumbuhkan motivasi belajar pada siswa. Lebih lanjut, berhubung dengan urgennya metode pembelajaran Contextual Teaching Learning dalam meningkatkan motivasi belajar siswa maka perlu juga dipahami tentang pengertian motivasi belajar itu sendiri. Adapun Pengertian motivasi dalam beberapa buku sumber diberikan pengertian secara berbeda dan beragam sesuai dengan cara pandang dari para penulis. Walaupun demikian kalau dilacak secara bahasa, maka istilah motivasi berasal dari bahasa latin yakni movere yang berarti menggerakkan, dorongan atau gejolak, motivasi berasal dari kata motif yang artinya sebagai daya penggerak, pendorong seseorang untuk melakukan aktifitas tertentu untuk mencapai suatu tujuan (Sardiman, 1999).

Motivasi dalam hal ini adalah kegiatan memberikan dorongan atau aktifitas kepada sesorang atau diri sendiri untuk berbuat sesuatu dalam rangka mencapai kepuasan atau tujuan (Djaali, 2008). Lebih lanjut, motivasi belajar adalah sesuatu atau kondisi yang menimbulkan dorongan atau semangat belajar atau semangat bergerak untuk melakukan aktivitas belajar Dimyati, \& Mudjiono (2009). Kondisi yang dimaksudkan tersebut dapat berhubungan dengan lingkungan, demikian juga yang dimaksud dengan lingkungan di sini adalah lingkungan sekolah. Sekolah sebagai suatu organisasai di dalamnya terdapat sejumlah orang yang berpartisipasi dan bekerjasama serta mempunyai peranan dan sangat penting untuk dapat digerakkan atau diberikan motivasi dalam rangka mencapai tujuan sekolah. Motivasi menjadi faktor penentu bagi perilaku orang-orang yang bekerja atau dapat dikatakan perilaku merupakan cerminan yang paling sederhana dari motivasi. Adapun menururt Mc Donald yang dikutip dalam Hamalik (2010) menjelaskan motivasi adalah suatu perubahan energi di dalam pribadi seseorang yang ditandai dengan timbulnya afektif dan reaksi untuk mencapai tujuan.

Kemudian kalau pengertian motivasi tersebut dikaitkan dengan tugas guru sebagai seorang motivator dalam bidang pendidikan di sekolah, ini berarti guru mampu menciptakan mampu menggunakan atau memilaih metode yang tepat dalam kegiatan belajar mengajar sehingga siswa tetap antusias dalam setiap pembelajaran. Hal ini sejalan dengan hasil pengabdian yang dilakukan oleh Sulastri, Maharani dan Sarilah (2020) dimana mereka menggunakan metode bercerita untuk memberikan pemahaman akan pentinggnya menjaga kesehatan dimasa pandemi demi mencegah tertularnya Covid-19. Dengan digunkannya 
metode pembelajaran Contextual Teaching Learning maka sumberdaya manusia terdorong dari dalam dirinya sendiri, memiliki harapan maupun terangsang untuk dapat melaksanakan tugasnya secara maksimal sehingga tujuan pembelajaran dapat tercapai dengan baik. Adapun dalam penerapan pembelajaran kontekstual maka dapat diuraikan model-model pembelajaran kontekstual yang meliputi: Belajar berbasis masalah, (Problem-based learning), belajar kooperatif (cooperative-learning), pembelajaran berbasis proyek (project-based learning), pembelajaran pelayanan(service-learnig), pembelajaran berbasis kerja (work-based-learning), pembelajaran pemahaman konsep (concept -learning), dan pembelajaran nilai (valuelearning), sehingga lebih lanjut diharapkan mampu menerapkannya dalam pembelajaran di lembaga TK/ PAUD.

Contextual Teaching Learning dapat diterapkan dalam kurikulum apa saja, bidang studi apa saja, dan kelas yang bagaimanapun keadaannya, pendekatan CTL dalam kelas cukup mudah secara garis besar langkahnya sebagai berikut: (1) kembangkan pemikiran bahwa anak akan belajar lebih bermakna dengan cara bekerja sendiri, dan mengkonstruksi sendiri pengetahuan dan keterampilan barunya; (2) laksanakan sejauh mungkin kegiatan inkuiri untuk semua topik; (3) kembaangkan sifat ingin tahu siswa dengan bertanya; (4) ciptakan masyarakat belajar; (5) hadirkan model sebagai contoh pembelajaran; (6) lakukan refleksi di akhir pertemuan; dan (7) lakukan penilaian.

Adapun tujuan yang diharapkan dari pelaksnaan kegiatan pengabdian masyarakat ini adalah untuk memberikan pemahaman kepada guru di TK Darul Muhsinin tentang pentingnya meningkatkan motivasi belajar siswa melalui pemanfaatan metode belajar Contextual Teaching Learning. Lebih lanjut, dari kegiatan ini diharapkan banyak siswa memiliki sikap positif dan motivasi belajarnya semakin meningkat.

\section{Metode Pengabdian}

Metode pelaksanaan kegiatan sebagai solusi untuk mengatasi permasalahan dengan menggunakan metode kemitraan, pengabdian ini bermitra dengan Lembaga TK Darul Muhsinin. Kegiatan pengabdian ini menempatkan mitra sebagai obyek sekaligus subyek dengan harapan adanya keaktifan dan keterbukaan dalam menyampaikan masalah dan kondisi yang diharapkan dari permasalahan. Mitra akan diberikan ruang untuk sharing tentang faktor penyebab atau motif dari permasalahan yang terjadi kemudian akan diedukasi apa yang seharusnya dilakukan untuk meningkatkan dan memberikan pelatihan pembelajaran Contextual Teaching Learning. Untuk mewujudkan hal tersebut, maka ditempuh langkahlangkah sebagai berikut: (1) persiapan yang meliputi: (a) memastikan kesiapan dan kesediaan mitra dengan lembaga) dan (b) memastikan lokasi kegiatan yang fleksibel dan nyaman bagi mitra; (2) pelatihan yang meliputi: (a) menyiapkan tema yang berhubungan dengan kontek pembelajaran yang digunakan untuk meningkatkan motivasi siswa; (b) menentukan waktu dan tempat pelaksanaan, (c) Menyiapkan narasumber yang berkompeten dibidang ini, (d) mengundang peserta yang terdiri dari guru TK guru SD kelas 1-3 di Desa Labulia, (e) melakukan tanya jawab antara peserta dengan narasumber, dan (f) melakukan praktek pengelolaan tema dalam pembelajaran.

\section{Hasil Pengabdian dan Pembahasan}

Pelaksanaan kegiatan pengabdian masyarakat ini dilakukan pada hari Sabtu, 15 Agustus 2020 di TK Darul Muhsinin Kabupaten Lombok Tengah. Sasaran utama dalam kegiatan pengabdian masyarakat ini adalah guru-guru di TK Darul Muhsinin akan tetapi banyak dari para orang tua beserta guru-guru SD di sekitar yang antusias untuk mengikuti 
kegiatan pengabdian masyarakat ini sehingga peserta menjadi lebih banyak. Kegiatan pengabdian masyarakat ini berupa pelatihan di dalam menerapkan metode belajar Contextual Teaching Learning bagi guru-guru di TK Darul Muhsinin yang dilakukan mulai tanggal 15 Agustus 2020 sampai dengan 15 November 2020. Adapun kegiatan awal yang dilakukan oleh Tim Dosen FIPP UNDIKMA adalah memberikan pemahaman terkait dengan metode belajar Contextual Teaching Learning berupa materi kepada para peserta. Setelah memberikan materi yang dibutuhkan oleh peserta maka selanjutnya Tim Dosen mengajak melakukan simulasi atau praktik terkait dengan cara menerapkan metode belajar Contextual Teaching Learning. Pelatihan yang dilakukan oleh Tim Dosen FIPP UNDIKMA dilakukan selama beberapa kali kegiatan sampai para peserta dapat melakukannya secara mandiri. Setelah para peserta yang dalam hal ini adalah guru-guru di TK Darul Muhsinin merasa sudah bisa menguasai metode tersebut maka Tim Dosen memberikan kesempatan kepada peserta untuk mulai bekerja secara mandiri dan tetap didampingi oleh Tim Dosen selama melakukan aktivitasnya 3 bulan kedepan. Dalam hal ini, pelatihan pembelajaran Contextual Teaching Learning dalam meningkatkan motivasi siswa merupakan kegiatan pembelajaran yang memotivasi guru untuk berusaha berinovasi dalam pembelajaran sehingga dapat meningkatkan motivasi siswa.

Adapun aktivitas yang dilakukan pada saat kegiatan pengabdian masyarakat yaitu dimana penyampaian materi pembelajaran Contextual Teaching Learning disampaikan oleh bapak Dr. I Made Sony Gunawan, M.Pd., dan praktik pembelajaran Contextual Teaching Learning disampaikan oleh ibu Sarilah, M.Pd., beserta dengan bapak Drs, I Made Gunawan, M.Pd., dan bapak Kholissus,sadi, M.Pd. Adapun dalam menyampaikan materi Tim Pengabdian menggunkan metode ceramah dan praktek dengan menggunakan media LCD/Infokus. Adapun peserta pelatihan pembelajaran Contextual Teaching Learning ini adalah Guru TK darul Muhsinin, Guru PAUD Harapan Bangsa Tandek, Guru SDN Batu Tinggang. Agar memberikan gambaran yang jelas terkait dengan kegiatan ini maka ditunjukkan melalui dokumentasi berupa foto-foto kegiatan selama pengabdian berlangsung yang dituangkan pada gambar 1.
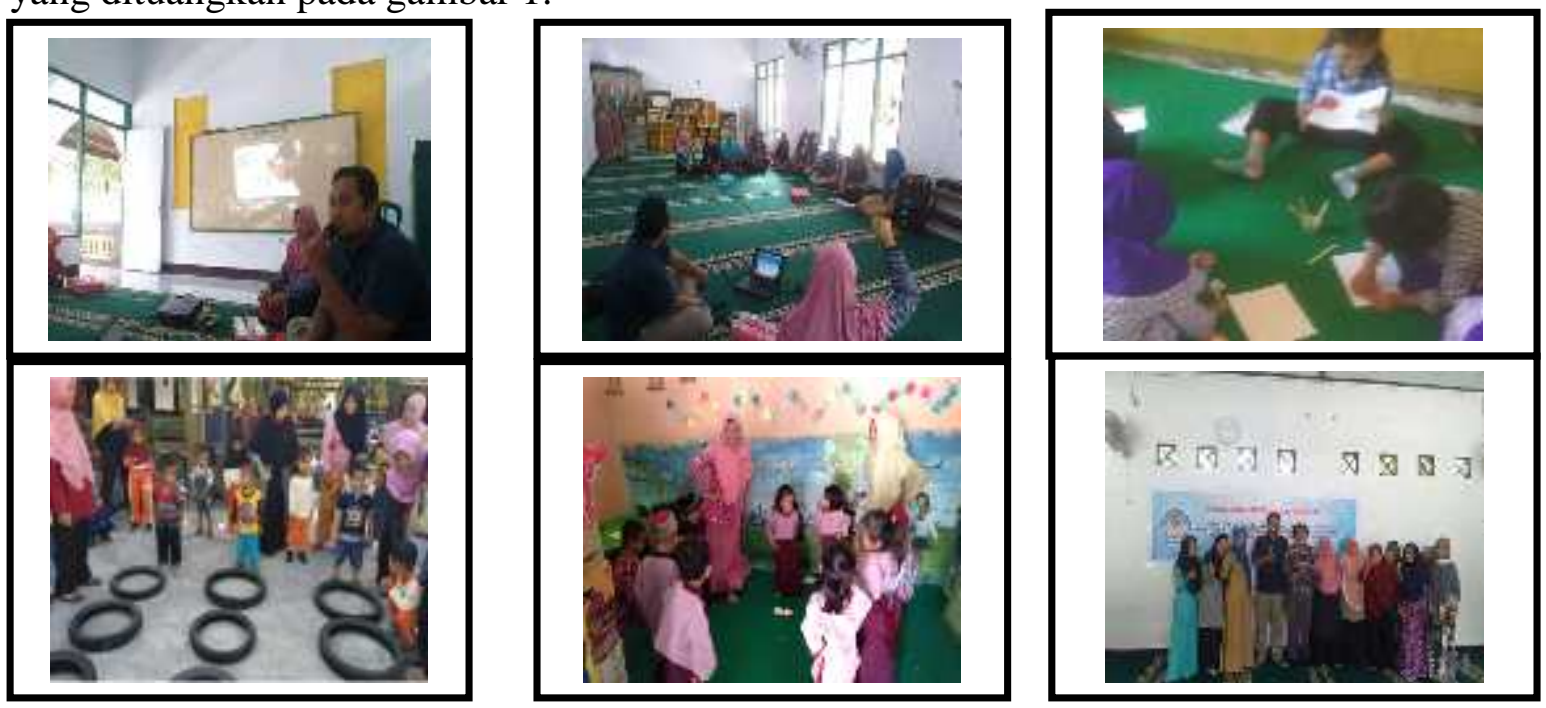

Gambar 1. Foto Kegiatan Pelatihan Metode Pembelajaran CTL

Hasil pengabdian ini dapat dilihat melalui kegiatan pengumpulan data yang dilakukan dengan wawancara dan tanya jawab serta pengamatan secara langsung selama kegiatan pengabdian pada masyarakat. Adapun hasil yang diperoleh selama kegiatan ini berlangsung 
yaitu dapat memberikan dampak sebagai berikut: (1) meningkatnya pengetahuan dan pemhaman guru tentang penerapan metode pembelajaran Contextual Teaching Learning; (2) meningkatnya keterampilan guru dalam menerapkan pembelajaran Contextual Teaching Learning; dan (3) meningkatnya motivasi belajar siswa yang dapat terlihat dari antusiasme siswa dalam kegiatan pembelajaran sehari-hari. Adapun dalam pengabdian ini ada beberapa faktor pendukung dan penghambat yang mempengaruhi hasil dari kegiatan. Lebih lanjut, faktor yang mendukung terlaksananya kegiatan pengabdian pada masyarakat ini adalah besarnya minat dan antusiasme pesrta selama kegiatan berlangsung dapat terlaksana dengan baik. Sedangkan faktor penghambatnya adalah keterbatasan waktu pelatihan yang dilakukan oleh tim dan lebih banyak waktu yang diluangkan pada kegiatan pendampingan. Lebih lanjut, melihat hasil pengabdian masyarakat yang positif bagi para guru dan siswa di TK Darul Muhsinin maka tindak lanjut yang dilakukan oleh Tim Dosen FIPP UNDIKMA adalah memberikan pendampingan selama tiga bulan kedepan dengan memberikan pelatihanpelatihan lainnya. Adapu tujuannya adalah untuk melihat apakah hasil dari pengabdian masyarakat ini dapat memberikan hasil yang optimal atau ada peningkatan seiring dengan perkembangan inovasi yang dihasilkan oleh guru di dalam menghasilkan cara-cara baru untuk meningkatkan motivasi belajar siswa.

\section{Kesimpulan}

Kesimpulan yang diperoleh dari kegiatan pengabdian ini antara lain: (1) dengan diadakannya pelatihan metode pembelajaran Contextual Teaching Learning bagi guru, maka semakin meningkatnya pemahaman pengetahuan serta mampu mengimplementasikan dalam kegiatan proses belajar mengajar; (2) dapat meningkatkan motivasi guru dalam merancang pembelajaran sebelum pelaksaan pembelajaran; dan (3) dapat meningkatkan antusiasme peserta didik, ketika pelaksaan pembelajaran, hal ini dapat dilihat dari antusiasme menjawab pertanyaan ibu guru dalam proses kegiatan berlangsung.

\section{Saran}

Berdasarkan hasil pengabdian yang sudah diperoleh maka disarankan kepada kepala sekolah agar memberikan kesempatan kepada para guru di dalam mengembangkan potensinya melalui kegiatan-kegiatan positif dimana salah satunya dengan mengikuti seminar pendidikan, pelatihan, dan penyuluhan. Adapun bagi guru sendiri diharapkan dapat memanfaatkan hasil pelatihan dari kegiatan pengabdian masayakat ini untuk mengembangkan potensi yang dimiliki di dalam menghasilkan media pembelajaran yang lebih menarik bagi para siswa sehingga siswa dapat meningkatkan motivasi belajarnya.

\section{Daftar Pustaka}

Dimyati, \& Mudjiono. (2009). Belajar dan pembelajaran. Jakarta: Rineka Cipta.

Djaali. (2008). Psikologi Pendidikan. Jakarta: PT. Bumi Aksara.

Hamalik, O. (2010). Proses belajar mengajar. Jakarta: Rineka Cipta.

Mulyasa. (2005). Menjadi guru profesional menciptakan pembelajaran kreatif dan menyenangkan. Bandung: PT. Remaja Rosdakarya.

Sardiman. (1999). Interaksi dan motivasi belajar mengajar: Pedoman bagi guru dan calon guru. Jakarta: Rajawali Press

Sulastri, N., Maharani, J., \& Sarilah, S. (2020). Mendongeng Bersama Anak Sebagai Upaya Pencegahan Covid-19. Jurnal Pengabdian UNDIKMA, 1(1). doi:https://doi.org/10.33394/jpu.v1i1.2691 